Journal of Engineering and Applied Sciences 14 (15): 5012-5021, 2019

ISSN: 1816-949X

(C) Medwell Journals, 2019

\title{
Multiple Optimal Coordinated Design Based on PSS and TCSC-POD Device for Damping Power System Oscillations with Compared Algorithms
}

\author{
Ali Nasser Hussain and Shaymaa Hamdan Shri \\ Department of Electrical Power Engineering Techniques, Electrical Engineering Technical College, \\ Middle Technical University, Baghdad, Iraq
}

\begin{abstract}
The aim of this study is to present develops a new design for damping LFO and improve performance the multiple damping coordinated designs based on (PSS) and (TCSC-POD) in the Single Machine Infinite Bus (SMIB) power system will be coordination performed in different ways. First, the individual controller's design PSS only then (TCSC-POD) only. Second, the dual coordinated controller's design between PSS and (TCSC-POD) controllers. The parameters of the damping controllers have been tuned by using a new algorithm known as the Dolphin Echolocation Optimization (DEO) that optimized the given eigenvalue-based objective function. The $\mathrm{DEO}$ has a strong ability to find the most optimal results it has few parameters, leads to excellent results with low computational efforts. Therefore, the DEO algorithm gave a better result compared with the PSO algorithm in all proposed controller and under different operation conditions. Where fewer oscillations, lower overshoot, a faster settling time and enhance the damping characteristics.
\end{abstract}

Key words: Low-Frequency Oscillation (LFO), Power System Stabilizer (PSS), Thyristor Controlled Series Compensator (TCSC), PSO algorithm, DEO algorithm, coordinated

\section{INTRODUCTION}

In power systems, usually low-frequency oscillation one of the most important problems faced by electrical engineers. Low-Frequency Oscillation (LFO) is generator rotor angle oscillations having a frequency between $(0.1-3.0) \mathrm{Hz}$ is a phenomenon of harmful, lead to in a loss of synchronism and system instability if adequate damping device is not provided (Kerendian, 2013).

The excitation system of the synchronous generator was using the Automatic Voltage Regulator (AVR) to regulate the terminal voltage, controlling the reactive power to enhance the system stability, maintain a steady state but is not useful for maintaining stability during transient conditions. Therefore, when the system exposed to disturbances, low-frequency oscillations continuous will show up for a long period. However, to overcome this effect, Power System Stabilizer (PSS) was installed on the synchronous generator to decreasing effect AVR, improve transfer stability of the power systems, damping low-frequency oscillation in local mode and enhancing the dynamic stability (Usman et al., 2012).

With increasing transmission line loading over long distances, the application of PSS might in some cases, not provide sufficient damping of the inter-area power oscillation in a multi-machine system. In these cases, Flexible AC Transmission Systems (FACTS) devices ware to use for controlling the power flow of the transmission lines and improving power oscillation damping in inter-area (Shayeghi et al., 2010).

The Thyristor Controlled Series Compensator (TCSC) is a series FACTS device which allows adjusting of the transmission line impedance, regulating the power flow, damping inter-area power oscillations and improving the transient stability (Falehi, 2012).

In damping mode, TCSC must be equipped with Power Oscillation Damping (POD) controller to generate the oscillation damping signal. Uncoordinated design of PSS and POD controllers in a power system equipped with PSS and TCSC-POD device stabilizers may cause destabilizing interactions. Therefore, the coordinated design of PSS and POD controllers will enhance system stability. Since, the coordinated design of (PSS and POD) is a nonlinear problem with a large number of design parameters it is appropriate to use nonlinear optimization techniques (Rezazadeh et al., 2010).

These techniques such as using Genetic Algorithm GA (Hadi et al., 2013). Gravitational Search Algorithm (GSA) (Eslami et al., 2011). Advanced adaptive PSO (Narne and Panda, 2014). Symbiotic Organisms Search algorithm (SOS) was successfully applied to solve optimization problems and compared with GA and PSO methods (Alomoush, 2017).

Corresponding Author: Ali Nasser Hussain, Department of Electrical Power Engineering Techniques, Electrical Engineering Technical College, Middle Technical University, Baghdad, Iraq 
This research introduces a new technique to adjust parameters of PSS and TCSC_POD in SMIB power system known as Dolphin Echolocation Optimization (DEO) algorithm. This algorithm is based on echolocation where it is considered as sonarused by Dolphins for search and hunting. This ability in Dolphin made her develop a new optimization method. Finally, simulation results proved, superior the (DEO) algorithm on the ( $\mathrm{PSO}$ ) algorithm in the individual and dual coordination controller designs under different operation conditions.

\section{MATERIALS AND METHODS}

Model of system: The Single Machine Infinite Bus SMIB power system is shown in Fig. 1 is considered in this study. The generator is equipped with a TCSC device has been placed in series with the transmission line to regulate the line impedance. The generator has a local load of admittance $(\mathrm{YL}=\mathrm{G}+\mathrm{jB})$ and the transmission line has an impedance $\left(\mathrm{Z}_{1}=\mathrm{R}+\mathrm{jX}\right) . \mathrm{V}_{\mathrm{t}}$ and $\mathrm{V}_{\mathrm{b}}$ terminal and infinite bus voltage, respectively (Sayyadnia et al., 2013).

Can be represented the generator by a third-order model comprising of the electromechanical swing equation and the generator internal voltage equation and the excitation system of the generator a first-order model (IEEE Type-ST1) as shown in Fig. 2.

The equations that describe the generator and excitation system have been represented in the following Eq. 1-8 (Jalilvand and Tirtashi, 2010):

$$
\begin{gathered}
\dot{\delta}=\omega_{\mathrm{b}}(\omega-1) \\
\omega=\frac{1}{\mathrm{M}}\left(\mathrm{P}_{\mathrm{m}}-\mathrm{P}_{\mathrm{e}}-\mathrm{D}(\omega-1)\right) \\
\dot{\mathrm{E}}_{\mathrm{q}}^{\prime}=\frac{1}{\mathrm{~T}_{\mathrm{do}}^{\prime}}\left(\mathrm{E}_{\mathrm{fd}}-\mathrm{E}_{\mathrm{q}}^{\prime}-\mathrm{id}\left(\mathrm{x}_{\mathrm{d}}-\mathrm{x}_{\mathrm{d}}^{\prime}\right)\right) \\
\dot{\mathrm{E}}_{\mathrm{fd}}=\frac{1}{\mathrm{~T}_{\mathrm{a}}}\left(\mathrm{k}_{\mathrm{a}}\left(\mathrm{v}_{\mathrm{ref}}-\mathrm{V}_{\mathrm{t}}+\mathrm{U}_{\mathrm{pss}}\right)-\mathrm{E}_{\mathrm{fd}}\right)
\end{gathered}
$$

Where:

$$
\begin{gathered}
\mathrm{P}_{\mathrm{e}}=v_{\mathrm{td}} \mathrm{i}_{\mathrm{d}}+v_{\mathrm{tq}} \mathrm{i}_{\mathrm{q}} \\
\mathrm{V}_{\mathrm{t}}=v_{\mathrm{td}}+\mathrm{j} v_{\mathrm{tq}} \\
v_{\mathrm{td}}=\mathrm{x}_{\mathrm{q}} \mathrm{i}_{\mathrm{q}} \\
v_{\mathrm{tq}}=\mathrm{E}^{\prime} \mathrm{q}-\mathrm{X}_{\mathrm{d}}^{\prime} \mathrm{i}_{\mathrm{d}}
\end{gathered}
$$

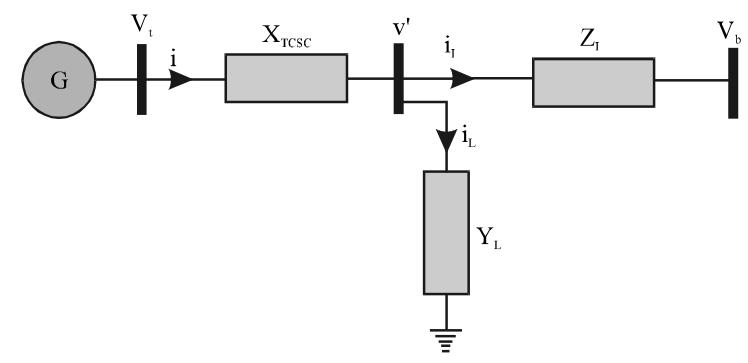

Fig. 1: SMIB power system equipped with TCSC device

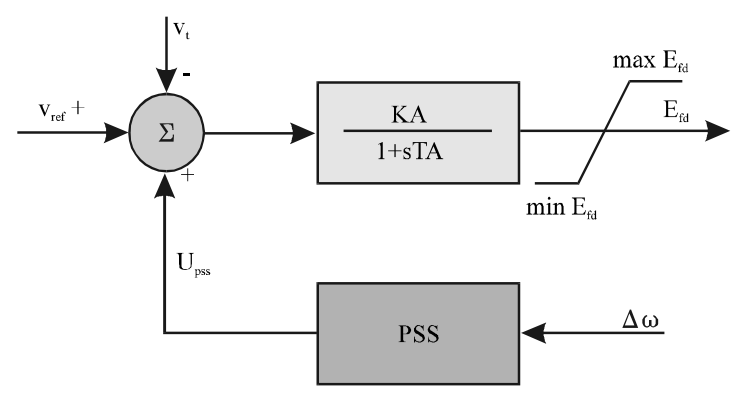

Fig. 2: Block diagram of excitation system with PSS

Where:

$\delta=$ The rotor angle

$\omega=$ The rotor speed

$\mathrm{P}_{\mathrm{m}}=$ The mechanical input Power

$\mathrm{P}_{\mathrm{e}}=$ Active Power

$\mathrm{E}_{\mathrm{q}}^{\prime}=$ The internal voltage

$\mathrm{E}_{\mathrm{fi}}=$ The Excitation voltage

$\mathrm{V}_{\text {ref }}=$ The reference voltage

A linear dynamic model is obtained by linearizing the nonlinear model round an operating condition. The linearized model of the power system is given as follows Eq. 9-15:

$$
\begin{gathered}
\Delta \dot{\delta}=\omega_{\mathrm{b}} \Delta \omega \\
\Delta \dot{\omega}=\frac{1}{\mathrm{M}}\left(-\Delta \mathrm{P}_{\mathrm{e}}-\mathrm{D} \Delta \omega\right) \\
\Delta \dot{\mathrm{E}}_{\mathrm{q}}^{\prime}=\frac{1}{\mathrm{~T}_{\mathrm{do}}^{\prime}}\left(\Delta \mathrm{E}_{\mathrm{fd}}-\Delta \mathrm{E}_{\mathrm{q}}^{\prime}-\Delta \mathrm{i}_{\mathrm{d}}\left(\mathrm{x}_{\mathrm{d}}-\mathrm{x}_{\mathrm{d}}^{\prime}\right)\right) \\
\Delta \dot{\mathrm{E}}_{\mathrm{fd}}=\frac{1}{\mathrm{~T}_{\mathrm{a}}}\left(\mathrm{k}_{\mathrm{a}}\left(\Delta \mathrm{V}_{\mathrm{ref}}-\Delta \mathrm{V}_{\mathrm{t}}+\mathrm{U}_{\mathrm{pss}}\right)-\Delta \mathrm{E}_{\mathrm{fd}}\right)
\end{gathered}
$$

Where:

$$
\begin{aligned}
& \Delta \mathrm{P}_{\mathrm{e}}=\mathrm{K}_{1} \Delta \delta+\mathrm{K}_{2} \Delta \mathrm{E}_{\mathrm{q}}^{\prime}+\mathrm{K}_{\mathrm{pTCSC}} \Delta \mathrm{X}_{\mathrm{TCSC}} \\
& \Delta \mathrm{E}_{\mathrm{q}}^{\prime}=\mathrm{K}_{4} \Delta \delta+\mathrm{K}_{3} \Delta \mathrm{E}_{\mathrm{q}}^{\prime}+\mathrm{K}_{\mathrm{qTCSC}} \Delta \mathrm{X}_{\mathrm{TCSC}}
\end{aligned}
$$




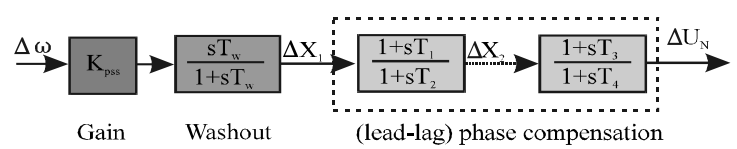

Fig. 3: Bock diagram of power system stabilizer

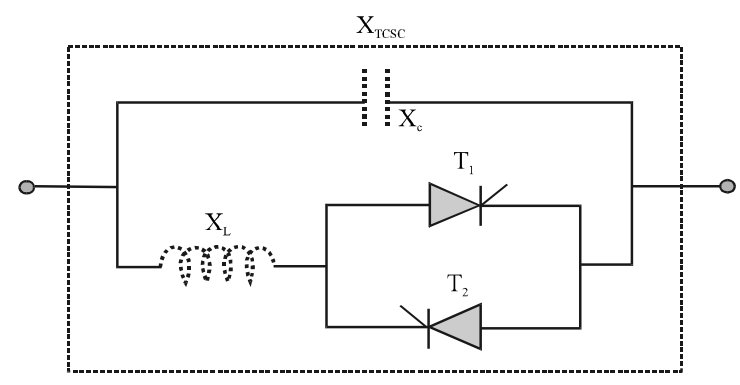

Fig. 4: Simple diagram of TCSC

$$
\Delta v_{\mathrm{t}}=\mathrm{K}_{5} \Delta \delta+\mathrm{K}_{6} \Delta \mathrm{E}_{\mathrm{q}}^{\prime}+\mathrm{K}_{\mathrm{vTCSC}} \Delta \mathrm{X}_{\mathrm{TCSC}}
$$

The constants $\mathrm{K}_{1}-\mathrm{K}_{6}, \mathrm{~K}_{\mathrm{p}}, \mathrm{K}_{\mathrm{q}}$ and $\mathrm{K}_{\mathrm{v}}$ are functions of the system parameters and the initial operating conditions.

Power System Stabilizer (PSS): Power System Stabilizer (PSS) an auxiliary device installed in an AVR excitation it provides a supplementary stabilizing signal in the excitation systems. And produce electrical torque in phase with rotor speed deviations. The block diagram of PSS shown in Fig. 3, consists of following blocks:

Gain block: It determines the amount of damping introduced by the stabilizer.

Washout block: It is a high pass filter that responds only to oscillations in speed and prevents the dc offset. From the view of the washout function, the value of $T_{w}$ is generally not critical and may be in the range of $1-20 \mathrm{sec}$. In this study it is fixed to $10 \mathrm{sec}$.

Phase compensator block: It is one or more (lead-lag) compensates for the phase lag caused by the AVR and the field circuit of the generator (Chakravarthi and Dasu, 2015).

Thyristor Controlled Series Capacitor (TCSC) controller: TCSC is a series FACTS device which allows adjusting of the transmission line impedance. It has several applications as regulating the power flow, improving transient stability, decrease sub-synchronous resonance and damping inter-area power oscillations.

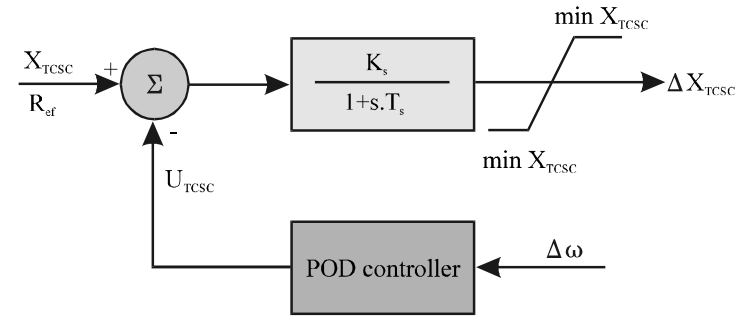

Fig. 5: Structure of the TCSC controller

Figure 4 shows the simple diagram of TCSC comprised of a fixed series capacitor bank in parallel with a Thyristors-Controlled Reactor (TCR). The series reactance is adjusted through a change of the firing angle. Controlling the firing angle of the thyristor can regulate the TCSC reactance and its degree of compensation (Tun and Swe, 2016).

The general structure of the TCSC controller is shown in Fig. 5. Power Oscillation Damping controller (POD) is like PSS in terms of form and composition, consists of a gain block, washout block and lead-lag phase compensation block (Panda and Padhy, 2007).

Design of optimal controllers PSS and TCSC-POD: To tune multiple power system damping controllers based on (PSS) and (TCSC-POD), linear model of the power system arranged in state space form as the following:

$$
\Delta \dot{\mathrm{X}}=\mathrm{A} \Delta \mathrm{X}+\mathrm{B} \Delta \mathrm{U}
$$

$$
\begin{gathered}
\Delta \mathrm{X}=\left[\Delta \delta \Delta \omega \Delta \mathrm{E}_{\mathrm{q}}^{\prime} \Delta \mathrm{E}_{\mathrm{fd}} \Delta \mathrm{X}_{\mathrm{TCSC}}\right]^{\mathrm{T}} \\
\Delta \mathrm{U}=\left[\Delta \mathrm{U}_{\mathrm{pss}} \Delta \mathrm{UT}_{\mathrm{CSC}}\right]^{\mathrm{T}} \\
{\left[\begin{array}{ccccc}
0 & \omega_{\mathrm{b}} & 0 & 0 & 0 \\
-\frac{\mathrm{K}_{1}}{\mathrm{M}} & -\frac{\mathrm{D}}{\mathrm{M}} & -\frac{\mathrm{K}_{2}}{\mathrm{M}} & 0 & -\frac{\mathrm{K}_{\mathrm{PTCSS}}}{\mathrm{M}} \\
-\frac{\mathrm{K}_{4}}{\mathrm{~T}_{\mathrm{do}}^{\prime}} & 0 & -\frac{\mathrm{K}_{3}}{\mathrm{~T}_{\mathrm{do}}^{\prime}} & -\frac{1}{\mathrm{~T}^{\prime} \mathrm{do}} & -\frac{\mathrm{Kq} \mathrm{Trsc}}{\mathrm{T}_{\mathrm{do}}} \\
-\frac{\mathrm{K}_{5} \mathrm{~K}_{\mathrm{a}}}{\mathrm{T}_{\mathrm{a}}} & 0 & -\frac{\mathrm{K}_{6} \mathrm{~K}_{\mathrm{a}}}{\mathrm{T}_{\mathrm{a}}} & -\frac{1}{\mathrm{~T}_{\mathrm{a}}} & -\frac{\mathrm{KVrrsc}_{\mathrm{a}}}{\mathrm{T}_{\mathrm{a}}} \\
0 & 0 & 0 & 0 & -\frac{1}{\mathrm{~T}_{\mathrm{s}}}
\end{array}\right]} \\
\mathrm{B}=\left[\begin{array}{ccccc}
0 & 0 & 0 & \frac{\mathrm{K}_{\mathrm{a}}}{\mathrm{T}_{\mathrm{a}}} & 0 \\
0 & 0 & 0 & 0 & -\frac{\mathrm{K}_{\mathrm{s}}}{\mathrm{T}_{\mathrm{s}}}
\end{array}\right]^{\mathrm{T}}
\end{gathered}
$$


The controller is (lead-lag) type can be described mathematically as (Hussain and Mijbas, 2016):

$$
\mathrm{U}_{(\mathrm{S})}=\mathrm{G}_{(\mathrm{S})} \mathrm{y}_{(\mathrm{S})}
$$

Where:

$\mathrm{G}_{(\mathrm{S})}=$ The transfer function of the controller

$\mathrm{y}_{(\mathrm{S})}=$ The measurement signal

$\mathrm{U}_{(\mathrm{s})}=$ The output signal from the controller which will provide additional damping by moving modes to the left

Equation 17 can be expressed in state space form as Eq. 18:

$$
\Delta \mathrm{X}_{\mathrm{C}}=\mathrm{A}_{\mathrm{C}} \Delta \mathrm{x}_{\mathrm{C}}+\mathrm{B}_{\mathrm{C}} \Delta \mathrm{u}
$$

where, $\Delta \mathrm{x}_{\mathrm{C}}$ is the state vector of the controller. The closed-loop system is given combining Eq. 16 with Eq. 18, we obtained Eq. 19:

$$
\begin{aligned}
& \Delta \dot{X}_{\mathrm{cl}}=\mathrm{A}_{\mathrm{cl}} \Delta \mathrm{X}_{\mathrm{cl}} \\
& \Delta \mathrm{x}_{\mathrm{Cl}}=\left[\begin{array}{c}
\Delta \mathrm{x} \\
\Delta \mathrm{x}_{\mathrm{C}}
\end{array}\right]
\end{aligned}
$$

The eigenvalues $(\lambda)$ and damping ratio $(\zeta)$ of the system are calculated by using Software MATLAB given in the command:

$$
\begin{aligned}
& \text { Lambda }=\operatorname{eig}(\mathrm{A}) \\
& {[\mathrm{Wn}, \text { Zeta,Pole }]=\operatorname{damp}\left(\mathrm{A}_{\mathrm{CI}}\right)} \\
& \mathrm{J}=\min (\text { Zeta })
\end{aligned}
$$

It is clear that the objective function J will identify the minimum value of the damping coefficient. The objective of the optimization process is to maximize $\mathrm{J}$ in order to appropriate damping for all modes, maximum $\mathrm{J}$ is searched within the limited range of control parameters as following:

$$
\begin{aligned}
& \mathrm{K}_{\mathrm{R}}{ }^{\min } \leq \mathrm{K}_{\mathrm{R}} \leq \mathrm{K}_{\mathrm{R}}{ }^{\max } \\
& \mathrm{T}_{\mathrm{Ri}}^{{ }^{\min }} \leq \mathrm{T}_{\mathrm{Ri}} \leq \mathrm{T}_{\mathrm{Ri}}{ }^{\max } \\
& \mathrm{T}_{\mathrm{RI}}{ }^{\min } \leq \mathrm{T}_{\mathrm{RI}} \leq \mathrm{T}_{\mathrm{RI}}{ }^{\max }
\end{aligned}
$$

Where:

$$
\begin{aligned}
\mathrm{R} & =\text { PSS and } \mathrm{X}_{\mathrm{TCSC}} \\
\mathrm{i} & =1,3 \\
\mathrm{I} & =2,4 \\
\mathrm{~K}_{\mathrm{R}} & =(0.01-100) \\
\mathrm{T}_{\mathrm{Ri}} & =(0.001-1) \\
\mathrm{T}_{\mathrm{RI}} & =(0.001-0.1)
\end{aligned}
$$

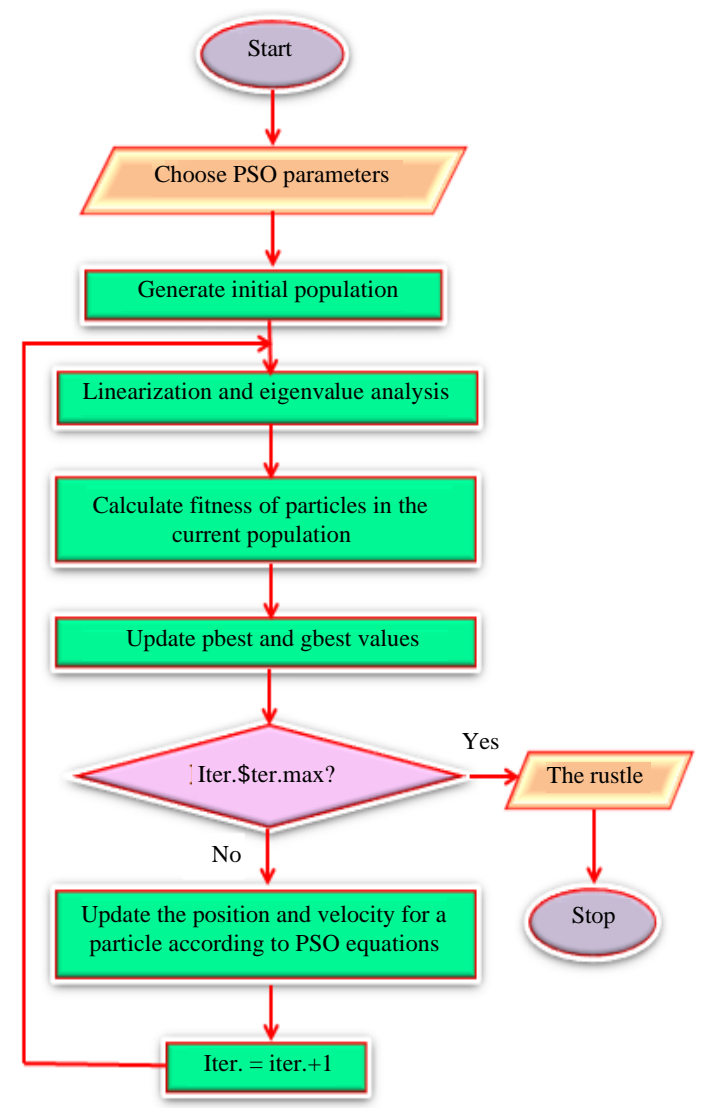

Fig. 6: Flowchart for particle swarm optimization

Particle Swarm Optimization (PSO): PSO is one of the methods among the many smart methods for solving the optimization problems developed in 1995 by Eberhart and Kennedy which was inspired by the social habit of bird flocking (Shivakumar and Lakshmipathi, 2010). The algorithmic steps involved in particle swarm optimization algorithm and flowcharts are as follows (Fig. 6 and Algorithm 1):

\section{Algorithm 1; PSO algorithm:}

Step 1: Choose the various parameters of PSO $\left(\mathrm{N}, \mathrm{C}_{1}, \mathrm{C}_{2}, \mathrm{~W}_{\min }, \mathrm{W}_{\max }\right.$ and iter $_{\max }$ )

Step 2: Initialize a population of particles with random positions and velocities

Step 3: Calculate optimization fitness function for each particle

Step 4: Compare the particles fitness value with its pbest for each individual particle

Step 5: Agree the particle that has the best fitness value. The value of its fitness function is represents the gbest

Step 6: Compute the new velocities and positions of the particles as follows:

The velocity of each agent (Eq. 20):

$$
\begin{gathered}
v \mathrm{i}^{\mathrm{k}+1}=\mathrm{w} \cdot v \mathrm{i}^{\mathrm{k}}+\mathrm{C}_{1} \cdot \mathrm{R}_{1}^{*}\left(\text { pbesti-si } \mathrm{s}^{\mathrm{k}}\right)+{ }_{0} \\
\mathrm{C}_{2} \cdot \mathrm{R}_{2}{ }^{*}\left(\text { gbesti-si } \mathrm{si}^{\mathrm{k}}\right)
\end{gathered}
$$


The following weighting function Eq. 21:

$$
\mathrm{w}=\left[\mathrm{w}_{\max }\right]-\left[\frac{\mathrm{w}_{\max }-\mathrm{w}_{\min }}{\mathrm{iter} \mathrm{r}_{\max }}\right] * \text { iter }
$$

The current position (Eq. 22):

$$
S_{i}^{k+1}=S_{i}^{k}+v_{i}^{k+1}
$$

Step 7: Repeat steps 3-6 still the stopping criterion of maximum generations is met

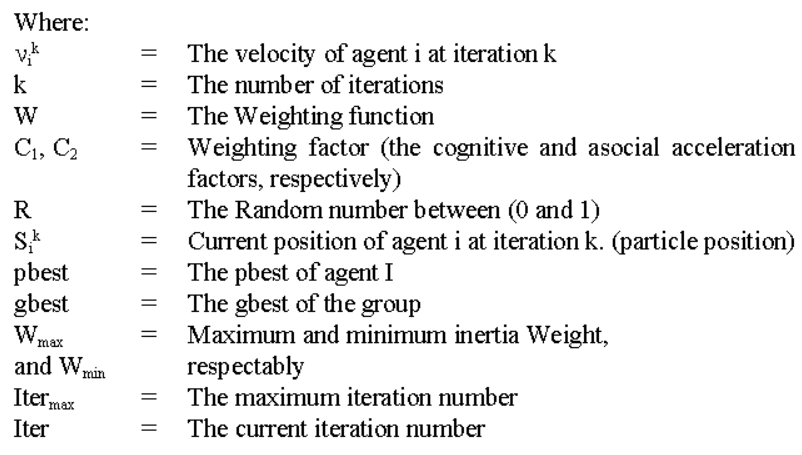

Dolphin Echolocation Optimization (DEO): By Kaveh and Farhoudi (2013) have developed a new optimization method named Dolphin Echolocation Optimization DEO algorithm (Kaveh and Farhoudi, 2013). This algorithm was inspired by hunting Dolphins. The Dolphin can send sound in the form of a click in different orientations and when this sound strikes a something, some part of the energy of the sound will reflect back to the Dolphin as the echo. Therefore, the Dolphin hears them and decides to make a decision at this time. Dolphin knows a range distance and orientation to the best bait. Tracking stage is started and Dolphin move to bait, continue sending sound and receiving echo until Dolphin access the bait. During this approach, the probability of hunting increases every time and search space reduced continuously. When Dolphin received an echo from different orientations it is time to process this information. Dolphin can decide to choose the next step which is a very important stage (Kaveh and Hosseini, 2014). This process is depicted in Fig. 7.

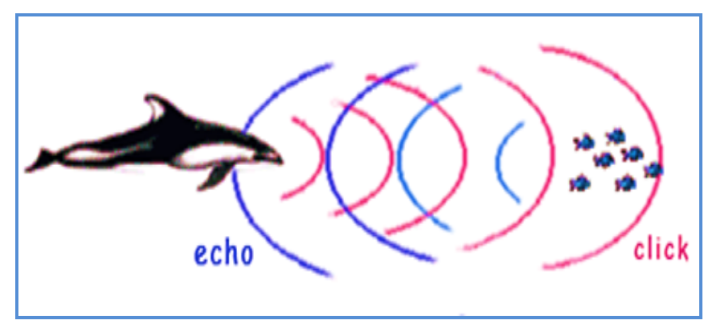

Fig. 7: Real Dolphins catching its prey
The steps for the tuning the algorithm and the flowchart of the DEO algorithm are show as follows (Kaveh and Farhoudi, 2013) (Algorithm 2):

\section{Algorithm 2; DEO algorithm:}

Step 1: "Initialization"

This step contains the initialization next:

A random Number of Locations (NL) and the

Number of Variables (NV) in the proposed

controller design. This step creating $\mathrm{L}_{\mathrm{NL}+\mathrm{NV}}$ matrix

Alternative matrix with dimension [MA $\times \mathrm{NV}$ ]

where MA is the maximum Alternative number in

the search space

The maximum number of loops $\mathrm{N}$

Step 2: "CF predefining and finding":

Set PP1 $=0.1$ which represent the convergence factor of the randomly selected location in the first loop use $\mathrm{CF}$ to find the predefined probability PP according to Eq. 23 :

$$
\mathrm{PP}(\text { Loopi })=\mathrm{PPI}+(1-\mathrm{PPI})((\text { Loopi-1) })) /
$$

$$
\text { (Loopsnumber-1) }
$$

Step 3: "Fitness calculation"

In this study proposed controller design is:

Objective function: $\mathrm{J}=\min$ (zeta)

Fitness function: Max $(J)$

Step 4: "Accumulated Fitness AF computation"

Calculate the $\mathrm{AF}$ for each $\mathrm{jth}$ variable in $\mathrm{L}(\mathrm{i}, \mathrm{j})$ location

via. using in Eq. 24:

$$
\mathrm{AF}_{(\mathrm{A}+\mathrm{k}) \mathrm{j}}=(1 / \mathrm{Re})(\mathrm{Re}-|\mathrm{k}|) \text { Fitness }_{\mathrm{i}}+\mathrm{AF}_{(\mathrm{A}+\mathrm{k}) \mathrm{j}}
$$

where, $\mathrm{AF}_{(\mathrm{A}+\mathrm{k}) \mathrm{j}}$ is the accumulative fitness of the $(\mathrm{A}+\mathrm{k})$ is the alternative to be chosen for the $\mathrm{jth}$ variable, $\mathrm{Re}$ is the effective radius in which accumulative fitness of the alternative $A$ 's neighbors are affected from its fitness ( $R e$ is recommended to be not more than quarter search spaces). Fitness (i) is the fitness of location $\mathrm{i}$

Step 5: "Best location finding"

Best location will own best $\mathrm{AF}$, thus, here terminate algorithm if termination criteria, else:

Find the alternative designation to the variable of best location

Let, the $\mathrm{AF}$ for best location alternative $=$ zero

Step 6: "Probability determination and allocation" Determine the probability as following:

$$
P(i, j)=\frac{A F_{i j}}{\sum_{i=1}^{L_{k j}} A F_{i j}}
$$

Suppose probability equals to PP for all variables of the best location Eq. 26 and 27 :

$$
\begin{gathered}
P(i, j)=P P \\
P(i, j)=(1-P P l o o p i) P(i, j)
\end{gathered}
$$

Step 7: "Next loop location selection"

Update of the location value with respect to the allocated probability of its alternative

Step 8: "Repetition"

Repeat the steps 2-7 even the maximum number of iterations is satisfied (Fig. 8) 


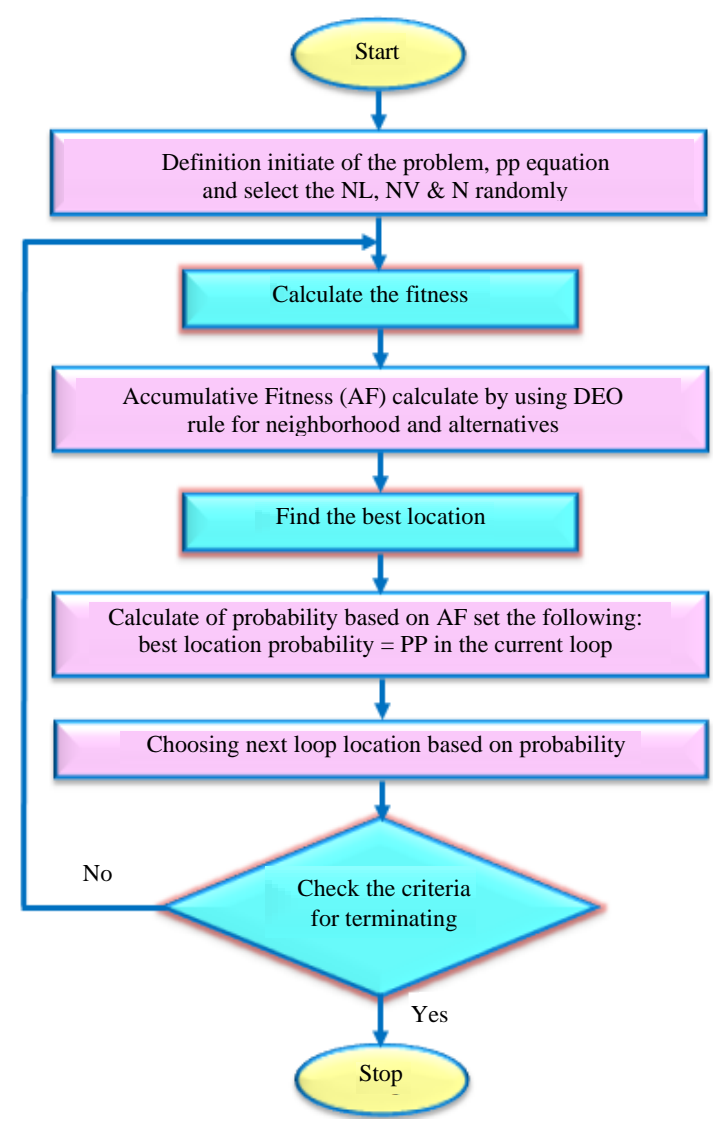

Fig. 8: The flowchart of the DEO algorithm

\section{RESULTS AND DISCUSSION}

This study reveals the simulation results coordinated optimal adjusting of PSS and TCSC-POD of the SMIB system by using DEO. To indicate the effectiveness of the DEO to optimally adjust POD and PSS control parameters, the results will be compared with the results obtained using the PSO. The user-provided parameters for the two optimization algorithms employed in this study are given in Table 1. In this study, three types of load are used to examine the system as given in Table 2. For each type of load, we consider the models four the following:

- The system without PSS and TCSC-POD controller

- The system with PSS only, (individual controller)

- The system with TCSC-POD only (individual controller)

- The system with PSS and TCSC-POD, (dual coordinated controller)

Now, the system without the controller is unstable because of the presence of positive modes $\left(\lambda_{1,2}\right.$ and $\left.\lambda_{1,2}\right)$

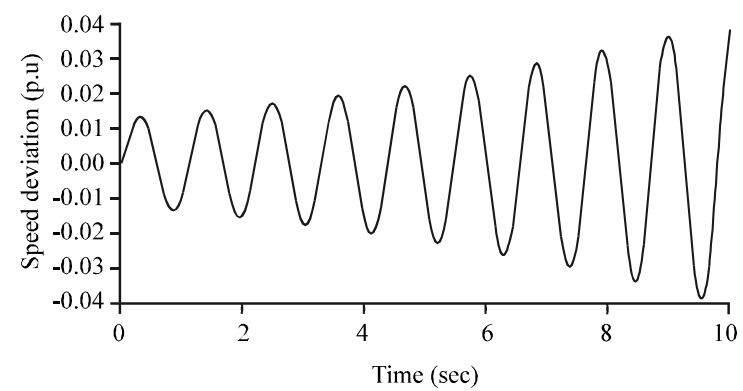

Fig. 9: Speed deviation without controller at NL

\begin{tabular}{lclc}
\multicolumn{4}{l}{ Table 1: The parameters of DEO and PSO } \\
DEO & & PSO & \\
\hline Variables & Values & Variables & Values \\
\hline NL & 60 & $\mathrm{~N}$ & 60 \\
Loop & 50 & Iteration & 50 \\
Variables & 5 & Variables & 5 \\
Nalt & 120 & $\mathrm{C}_{1}, \mathrm{C}_{2}$ & 2 \\
& & $\mathrm{~W}$ & 0.3 \\
\hline
\end{tabular}

Table 2: System loading conditions

\begin{tabular}{lcc}
\hline Loading conditions & P (p.u) & Q (p.u) \\
\hline Nominal Load (NL) & 1.0 & 0.20 \\
Light Load (LL) & 0.3 & 0.10 \\
Heavy Load (HL) & 1.2 & 0.28 \\
\hline
\end{tabular}

Table 3: Eigenvalues $(\lambda)$ without controller

\begin{tabular}{ll}
\hline Load & Eigenvalues $(\lambda)$ \\
\hline Nominal Load (NL) & \\
$\lambda_{1}, \lambda_{2}$ & $0.1189 \pm 5.7988 \mathrm{i}$ \\
$\lambda_{3}, \lambda_{4}$ & $-10.2168 \pm 3.3475 \mathrm{i}$ \\
$\lambda_{5}$ & $-20.0000+0.0000 \mathrm{i}$ \\
Light Load (LL) & \\
$\lambda_{1}, \lambda_{2}$ & $-0.0316 \pm 5.2534 \mathrm{i}$ \\
$\lambda_{3}, \lambda_{4}$ & $-10.0663 \pm 3.8481 \mathrm{i}$ \\
$\lambda_{5}$ & $-20.0000+0.0000 \mathrm{i}$ \\
Heavy Load (HL) & \\
$\lambda_{1}, \lambda_{2}$ & $0.6961 \pm 4.4721 \mathrm{i}$ \\
$\lambda_{3}, \lambda_{4}$ & $-10.7940 \pm 3.9274 \mathrm{i}$ \\
$\lambda_{5}$ & $-20.0000+0.0000 \mathrm{i}$ \\
\hline
\end{tabular}

of nominal and heavy loading, respectively as shown in Table 3. The speed deviation response unstable for loading conditions without control is shown in Fig. 9-11, respectively.

Figure 12-14 shown the speed deviation responses of SMIB with the proposed individual controller (PSS) under nominal, light and heavy load, respectively. It can be seen that, the PSS controller is weak in damping the system Oscillations. Though, DEO was better than PSO in terms of overshoot and settling time.

Figure 15-17 show the speed deviation responses of SMIB with the proposed individual controller TCSC-POD to the damping of oscillation. It can be seen that the 


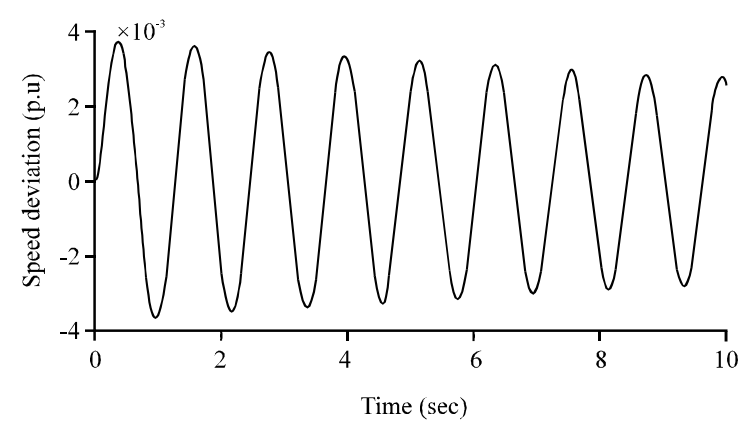

Fig. 10: Speed deviation without controller at LL

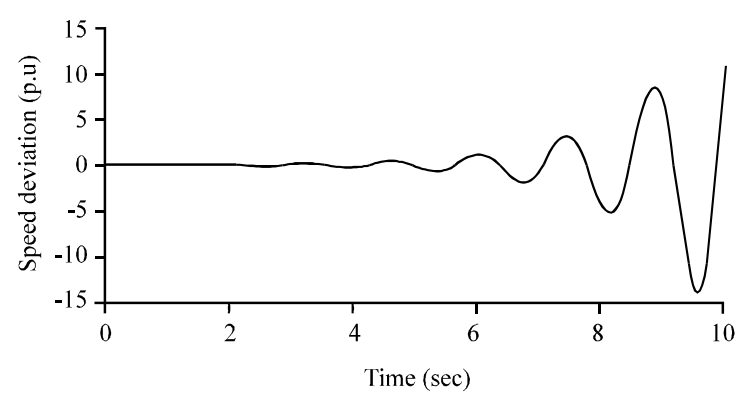

Fig. 11: Speed deviation without controller at $\mathrm{HL}$

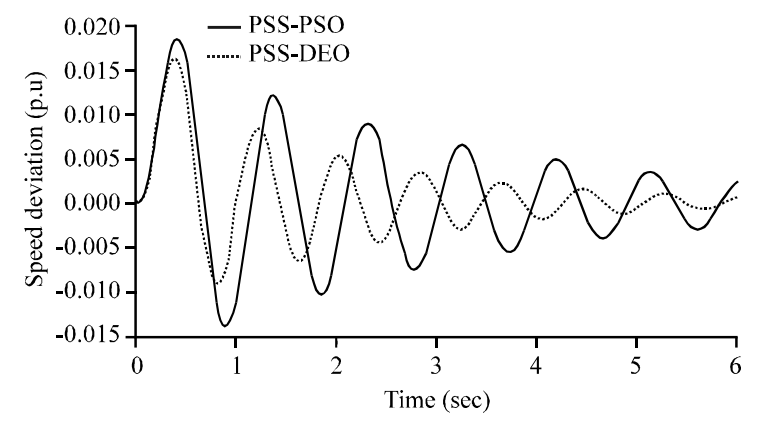

Fig. 12: Speed deviation with PSS at NL

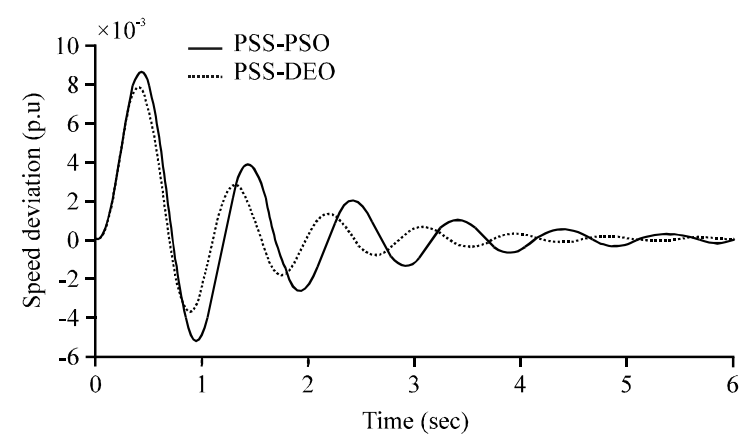

Fig. 13: Speed deviation with PSS at LL

controller is effective in damping the system oscillations. Where the speed deviation response via. using DEO

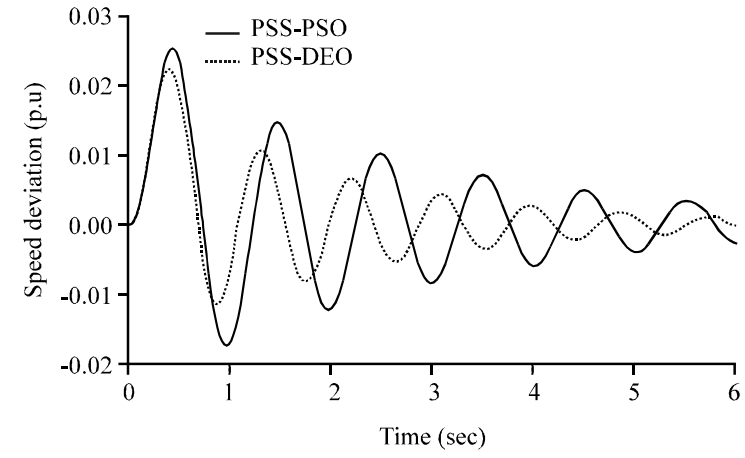

Fig. 14: Speed deviation with PSS at HL

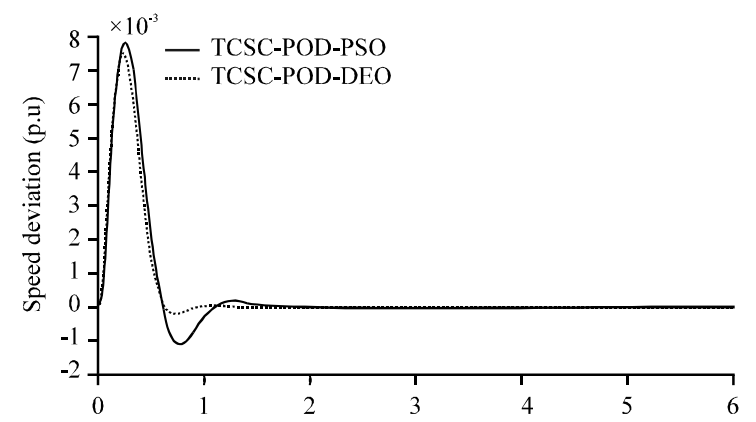

Fig. 15: Speed deviation with TCSC-POD at NL

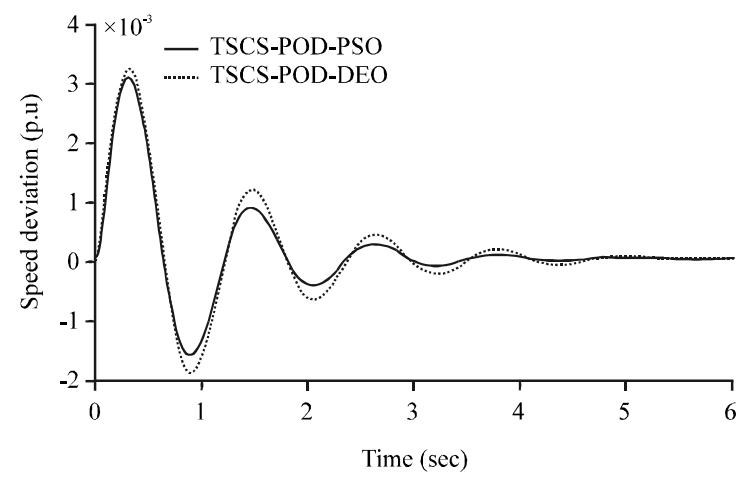

Fig. 16: Speed deviation with TCSC-POD at LL

algorithm show improvement in the damping parameters overshoot and settling time compared with $\mathrm{PSO}$, under all load conditions.

Figure 18-20 shows the speed deviation responses of SMIB with the proposed coordinated design between PSS and TCSC-POD. It can be seen that the better dynamic response is obtained by using coordinated design. As well using DEO is most effective from $\mathrm{PSO}$ it has less number of oscillations and much faster responses from PSO. 
Table 4: The optimal parameter settings of the PSO and proposed DEO controller with NL

\begin{tabular}{|c|c|c|c|c|c|c|}
\hline Controller types & Zeta $(\zeta)$ & $\mathrm{K}$ & $\mathrm{T}_{1}$ & $\mathrm{~T}_{2}$ & $\mathrm{~T}_{3}$ & $\mathrm{~T}_{4}$ \\
\hline \multicolumn{7}{|l|}{ PSS } \\
\hline DEO & 0.0662006 & 34.2720 & 0.8659 & 0.0010 & 0.9822 & 0.0004 \\
\hline PSO & 0.0490588 & 16.4697 & 0.9906 & 0.0012 & 0.9167 & 0.0010 \\
\hline \multicolumn{7}{|l|}{ TCSC-POD } \\
\hline DEO & 0.5786264 & 95.7350 & 0.4275 & 0.0059 & 0.7614 & 0.0097 \\
\hline PSO & 0.5388595 & 78.4528 & 0.0111 & 0.0003 & 0.2555 & 0.0043 \\
\hline \multicolumn{7}{|c|}{$\mathrm{PSS}^{*}$ and TCSC-POD ${ }^{* *}$} \\
\hline \multirow[t]{2}{*}{ DEO } & 0.6826098 & $1.1972^{*}$ & $0.1639^{*}$ & $0.0974^{*}$ & $0.1544^{*}$ & $0.0664^{*}$ \\
\hline & & $99.5217^{* *}$ & $0.8577^{* *}$ & $0.0008^{* *}$ & $0.6990^{* *}$ & $0.0063^{*+}$ \\
\hline \multirow[t]{2}{*}{ PSO } & 0.6124479 & $0.2710^{*}$ & $0.9636^{*}$ & $0.0986^{*}$ & $0.9643^{*}$ & $0.0013^{*}$ \\
\hline & & $90.8130^{* *}$ & $0.0593^{* *}$ & $0.0027^{* *}$ & $0.7458^{* *}$ & $0.0091^{*+}$ \\
\hline
\end{tabular}

Table 5: The optimal parameter settings of the PSO and proposed DEO controller with LL

\begin{tabular}{|c|c|c|c|c|c|c|}
\hline Controller types & Zeta $(\zeta)$ & $\mathrm{K}$ & $\mathrm{T}_{1}$ & $\mathrm{~T}_{2}$ & $\mathrm{~T}_{3}$ & $\mathrm{~T}_{4}$ \\
\hline \multicolumn{7}{|l|}{$\overline{\text { PSS }}$} \\
\hline DEO & 0.1200169 & 69.3689 & 0.9219 & 0.0003 & 0.9855 & 0.0004 \\
\hline PSO & 0.1054113 & 43.8585 & 0.0060 & 0.0016 & 0.9328 & 0.0027 \\
\hline \multicolumn{7}{|l|}{ TCSC-POD } \\
\hline DEO & 0.1961967 & 99.9237 & 0.7062 & 0.0023 & 0.8661 & 0.0015 \\
\hline PSO & 0.1777892 & 80.8783 & 0.2450 & 0.0019 & 0.7790 & 0.0041 \\
\hline \multicolumn{7}{|c|}{ PSS $^{+}$and TCSC-POD ${ }^{+*}$} \\
\hline \multirow[t]{2}{*}{$\mathrm{DEO}$} & 0.2437056 & $31.5857^{*}$ & $0.0680^{*}$ & $0.0013^{*}$ & $0.9105^{*}$ & $0.0029^{*}$ \\
\hline & & $96.0546^{* *}$ & $0.2921^{* *}$ & $0.0063^{* *}$ & $0.6362^{* *}$ & $0.0007^{* *}$ \\
\hline \multirow[t]{2}{*}{ PSO } & 0.1911991 & $6.6573^{*}$ & $0.0163^{*}$ & $0.0873^{*}$ & $0.5044^{*}$ & $0.0024^{*}$ \\
\hline & & $98.7623^{* *}$ & $0.1247^{* *}$ & $0.0081^{* *}$ & $0.6077^{* *}$ & $0.0053^{* *}$ \\
\hline
\end{tabular}

Table 6: The optimal parameter settings of the PSO and proposed DEO controller with $\mathrm{HL}$

\begin{tabular}{|c|c|c|c|c|c|c|}
\hline Controller types & Zeta $(\zeta)$ & $\mathrm{K}$ & $\mathrm{T}_{1}$ & $\mathrm{~T}_{2}$ & $\mathrm{~T}_{3}$ & $\mathrm{~T}_{4}$ \\
\hline \multicolumn{7}{|l|}{$\overline{\text { PSS }}$} \\
\hline DEO & 0.0695892 & 41.9013 & 0.9695 & 0.0005 & 0.7378 & 0.0005 \\
\hline PSO & 0.0585520 & 29.5408 & 0.9970 & 0.0011 & 1.0000 & 0.0010 \\
\hline \multicolumn{7}{|l|}{ TCSC-POD } \\
\hline DEO & 0.7192867 & 86.7787 & 0.9808 & 0.0060 & 0.9674 & 0.0008 \\
\hline PSO & 0.7082701 & 70.6609 & 0.4746 & 0.0041 & 0.1586 & 0.0102 \\
\hline \multicolumn{7}{|c|}{ PSS $^{*}$ and TCSC-POD ${ }^{* *}$} \\
\hline \multirow[t]{2}{*}{ DEO } & 0.7793273 & $6.6652^{*}$ & $0.7158^{*}$ & $0.0240^{*}$ & $0.1209^{*}$ & $0.0363^{*}$ \\
\hline & & $96.5916^{* *}$ & $0.4601^{* *}$ & $0.0013^{* *}$ & $0.5370^{* *}$ & $0.0067^{* *}$ \\
\hline \multirow[t]{2}{*}{ PSO } & 0.7204408 & $1.9839^{*}$ & $0.0920^{*}$ & $0.0022^{*}$ & $0.9234^{*}$ & 0.0076 \\
\hline & & $80.7156^{* *}$ & $0.7852^{* *}$ & $0.0012^{* *}$ & $0.8743^{* *}$ & $0.0117^{* *}$ \\
\hline
\end{tabular}

${ }^{*, * *}$ Values are significant

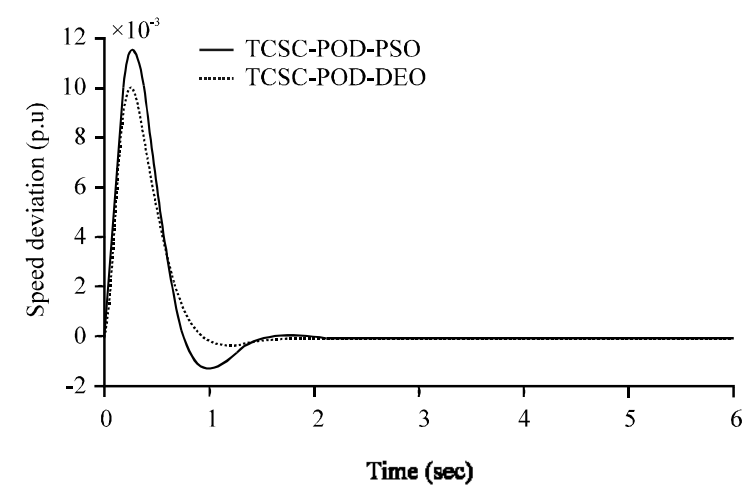

Fig. 17: Speed deviation with TCSC-POD at HL

Table 4-6 show the values of final for the optimal parameter settings DEO compared with PSO with damping ratio. From tables it can be seen that damping ratio by

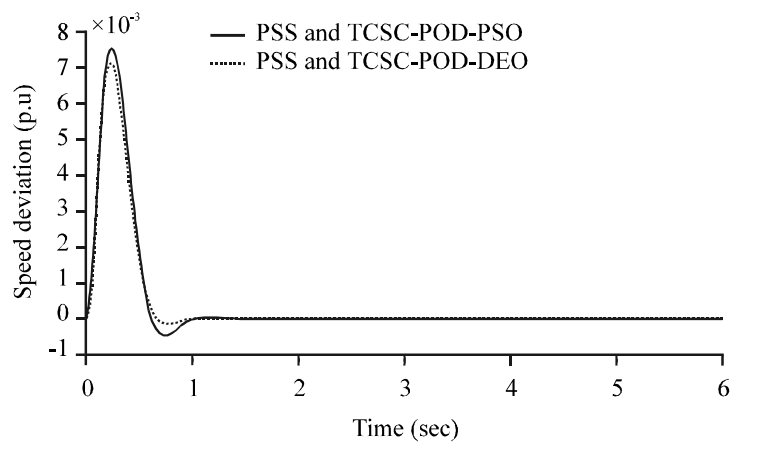

Fig. 18: Speed deviation with PSS and TCSC-POD at HL

using DEO is greater compared with PSO. Therefore, be damping LFO better and faster when using the DEO algorithm (Appendix). 


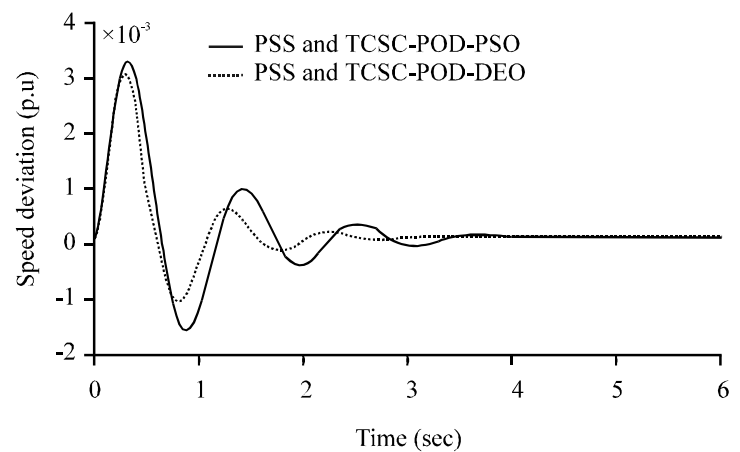

Fig. 19: Speed deviation with PSS and TCSC-POD at LL

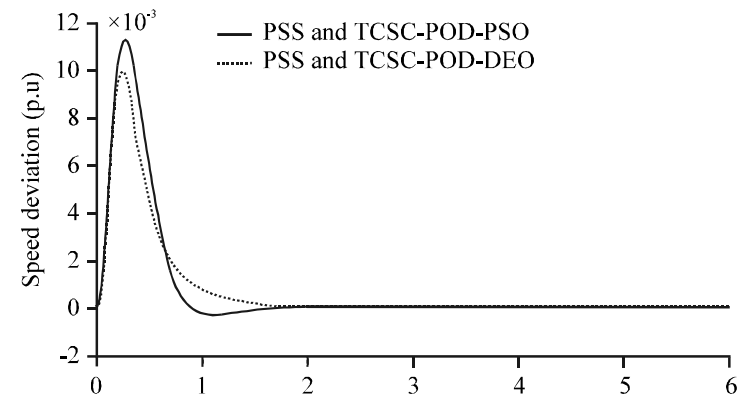

Fig. 20: Speed deviation with PSS and TCSC-POD at HL

\section{CONCLUSION}

To enhance the stability of the system and the system damping performance is improved, supplementary damping controller is required connected with a SMIB system in the form of PSS and TCSC- POD as described in this study. In order to achieve better performance and optimal response of the controller, a new optimization method named Dolphin Echolocation Optimization (DEO) algorithm was used. DEO algorithm is run to the adjust optimal parameters from individual and dual coordinated controller. The simulation results confirmed that the $\mathrm{DEO}$ provide robust damping and effective of individual and dual coordinated controls compared with PSO algorithm and under all different loading conditions where they provide higher damping of low-frequency oscillations, the settling time is faster, a less value of overshoots and improve the system stability best than the using PSO algorithm.

\section{APPENDIX}

Power system parameters:

$\begin{aligned} \mathrm{M} & =9.26 \\ \mathrm{D} & =0\end{aligned}$

$\begin{aligned} \mathrm{T}^{\prime}{ }_{\text {do }} & =7.76 \\ \mathrm{X}_{\mathrm{d}} & =0.973 \\ \mathrm{X}_{\mathrm{q}} & =0.55 \\ \mathrm{X}_{\mathrm{d}} & =0.19 \\ \mathrm{~K}_{\mathrm{A}} & =50 \\ \mathrm{~T}_{\mathrm{A}} & =0.05 \\ \mathrm{X} & =0.997 \\ \mathrm{R} & =0.034 \\ \mathrm{G} & =0.249 \\ \mathrm{~B} & =0.262 \\ \mathrm{~V}_{\mathrm{t}} & =1.05 \\ \mathrm{~K}_{s} & =1 \\ \mathrm{~T}_{s} & =0.05\end{aligned}$

$\mathrm{T}_{\mathrm{s}} \quad=0.05$

\section{REFERENCES}

Alomoush, M., 2017. Concurrent optimal design of TCSC and PSS using symbiotic organisms search algorithm. Turk. J. Electr. Eng. Comput. Sci., 25: 3904-3919.

Chakravarthi, M. and M.B. Dasu, 2015. Design of power system stabilizer for small signal stability improvement. Intl. J. Res. Sci. Eng. Technol., 2: 19-25.

Eslami, M., H. Shareef, A. Mohamed and M. Khajehzadeh, 2011. PSS and TCSC damping controller coordinated design using GSA. Intl. Conf. Adv. Energy Eng., 14: 763-769.

Falehi, A.D., 2012. Simultaneous coordinated design of TCSC-based damping controller and AVR Based on PSO technique. Elect. Rev., 88: 136-140.

Hadi, S.P., H.I. Wiennetou and R.F. Mochamad, 2013. TCSC power oscillation damping and PSS design using genetic algorithm modal optimal control. Intl. J. Eng. Comput. Sci., 13: 23-30.

Hussain, A.N. and A.F. Mijbas, 2016. Damping improvement of multiple damping controllers by using optimal coordinated design based on PSS and FACTS-POD in a multi-machine power system. J. Univ. Babylon, 24: 733-732.

Jalilvand, A. and M.R.S. Tirtashi, 2010. Design of output feedback controller for PSS and TCSC by GA to improve the damping of power system oscillations. Proceedings of the International Conference on Power and Energy, November 29-December 1, 2010, IEEE, Kuala Lumpur, Malaysia, ISBN:978-1-4244-8947-3, pp: 178-182.

Kaveh, A. and N. Farhoudi, 2013. A new optimization method: Dolphin echolocation. Adv. Eng. Software, 59: 53-70.

Kaveh, A. and P. Hosseini, 2014. A simplified dolphin echolocation optimization method for optimum design of trusses. Iran Univ. Sci. Technol., 4: 381-397. 
Kerendian, R.F., 2013. Performance analysis of smib and design power system stabilizer to improve stability based on MATLAB/SIMULINK. Intl. J. Eng. Sci. Res., 3: 625-632.

Narne, R. and P.C. Panda, 2014. PSS with multiple facts controllers coordinated design and real-time implementation using advanced adaptive PSO. World Acad. Sci. Eng. Technol. Intl. J. Electr. Comput. Energetic Electron. Commun. Eng., 8: 137-147.

Panda, S. and N.P. Padhy, 2007. MATLAB/SIMULINK based model of single-machine infinite-bus with TCSC for stability studies and tuning employing GA. Int1. J. Comput. Sci. Eng., 1: 50-59.

Rezazadeh, A., M. Sedighizadeh and A. Hasaninia, 2010. Coordination of PSS and TCSC controller using modified particle swarm optimization algorithm to improve power system dynamic performance. J. Zhejiang Univ. Sci. C., 11: 645-653.
Sayyadnia, M.H., M. Sedighizadeh and A. Panahi, 2013. Coordination design PSS and TCSC controller for power system stability improvement using CLA-PSO algorithm. World Appl. Sci. J., 20: 1156-1165.

Shayeghi, H., A. Safari and H.A. Shayanfar, 2010. PSS and TCSC damping controller coordinated design using $\mathrm{PSO}$ in multi-machine power system. Energy Convers. Manage., 51: 2930-2937.

Shivakumar, R. andR. Lakshmipathi, 2010. Implementation of an innovative bio inspired GA and PSO algorithm for controller design considering steam GT dynamics. Intl. J. Comput. Sci. Issues, 7: 18-28.

Tun, T.T. and P.L. Swe, 2016. Comparison of TCSC and STATCOM for damping power system oscillations. Am. Sci. Res. J. Eng. Technol. Sci., 26: 257-269.

Usman, J., M.W. Mustafa and G. Aliyu, 2012. Design of AVR and PSS for power system stability based on iteration particle swarm optimization. Intl. J. Eng. Innovative Technol., 2: 307-314. 